\title{
Dynamic radiostereometric analysis for evaluation of hip joint pathomechanics
}

\author{
Lars Hansen ${ }^{2,3^{*}}$ (D), Sepp de Raedt ${ }^{4}$, Peter Bo Jørgensen ${ }^{2,3}$, Bjarne Mygind-Klavsen ${ }^{1}$, Bart Kaptein ${ }^{5}$ \\ and Maiken Stilling 2,3
}

\begin{abstract}
Background: Dynamic RSA (dRSA) enables non-invasive 3D motion-tracking of bones and may be used to evaluate in-vivo hip joint kinematics including hip pathomechanics such as femoroacetabular impingement (FAI) and the biomechanical effects of arthroscopic cheilectomy and -rim trimming (ACH).

The study aim was to evaluate the kinematic changes in the hip joint after ACH.

Methods: Seven non-FAl affected human cadaveric hips were CT-scanned and CT-bone models were created. dRSA recordings of the hip joints were acquired at five frames/s during passive flexion, adduction to stop, and internal rotation to stop (FADIR). ACH was performed and dRSA was repeated. dRSA images were analyzed using model-based RSA. Hip joint kinematics before and after ACH were compared pairwise. The volume of removed bone was quantified and compared to the postoperative range of motion (ROM).

Results: Mean hip internal rotation increased from 19.1 to $21.9^{\circ}\left(p=0.04, \Delta 2.8^{\circ}\right.$, SD 2.7) after ACH surgery. Mean adduction of $3.9^{\circ}$ before and $2.7^{\circ}$ after $\mathrm{ACH}$ surgery was unchanged $\left(p=0.48, \Delta-1.2^{\circ}\right.$; SD 4.3$)$. Mean flexion angles during dRSA tests were $82.4^{\circ}$ before and $80.8^{\circ}$ after ACH surgery, which were similar $(p=0.18$, $\left.\Delta-1.6^{\circ}, S D=2.7\right)$. No correlation between volume of removed bone and ROM was observed.

Conclusions: A small increase in internal rotation, but not in adduction, was observed after arthroscopic cheilectomy and -rim trimming in cadaver hips. The hip flexion angle of the FADIR test was reproducible. dRSA kinematic analysis is a new and clinically applicable method with good potential to evaluate hip joint kinematics and to test FAl pathomechanics and other surgical corrections of the hip.
\end{abstract}

Keywords: Femoroacetabular impingement, Radiostereometric analysis, Biomechanics, Pathomechanics, Arthroscopy, Range of motion, Basic science, Hip

\section{Background}

Femoroacetabular impingement (FAI) is caused by an abnormality in the acetabular shape or orientation (Pincertype), by a shape-abnormality in the proximal femur (Cam-type) or by a combination of the two (mixed-type) (Agricola et al. 2013; Beck et al. 2005). FAI most often presents in healthy, physically active, young persons (predominantly male) in the age range of 20-30 years (Ganz et al. 2003). It is recognized as a common cause of pain and early development of osteoarthritis (Larson et al. 2016; Kowalczuk et al. 2015). The reported prevalence of

\footnotetext{
* Correspondence: larshansen33@hotmail.com

${ }^{2}$ Orthopedic Research Unit, Aarhus University Hospital, Tage-Hansens Gade 2, building 10A, Office 13, 8000 Aarhus, Denmark

${ }^{3}$ Department of Clinical Medicine, Aarhus University, Aarhus, Denmark

Full list of author information is available at the end of the article
}

asymptomatic FAI in radiographs is $23-32 \%$ for CAM lesions and 43-67\% for pincer lesions (Frank et al. 2015; Diesel et al. 2015). Studies show that physical impairments for individuals with symptomatic FAI primarily consist of motions bringing the hip towards impingement. Typically impaired daily activities are stairclimbing, squat and restrictions in frontal, transverse and sagittal hip motion during gait (Diamond et al. 2015a; Diamond et al. 2015b). Further, studies have shown that FAI patients lack hip muscle strength compared to normal controls (Casartelli et al. 2011; Freke et al. 2016).

The preferred surgical treatment of FAI is by arthroscopic cheilectomy and -rim-trimming $(\mathrm{ACH})$ (Nwachukwu et al. 2015). Excess bone is removed in the head-neck transition of the femur bone and in 
the anterolateral region of the acetabular rim. Arthroscopic technique is superior to an open approach based on higher postoperative general health-related quality of life (HRQoL) score (Nwachukwu et al. 2015) and an increased patient satisfaction of $82 \%$ (Sansone et al. 2016). Still the main reason for revision after $\mathrm{ACH}$ procedure is failure to identify and/or reshape the affected areas in the joint adequately (Heyworth et al. 2007; Ross et al. 2014; Philippon et al. 2007; Larson et al. 2014).

Earlier studies have investigated joint kinematics related to FAI pre- and postoperatively. Simulation studies using CT-reconstructed bone models for simulation of impingement positions have been performed (Bedi et al. 2011; Kubiak-Langer et al. 2007; Sampson \& Safran 2015). Limitations of this method are that it commonly assumes range of motion (ROM) to be governed by bone-bone contact, and they do not track the exact in vivo motions of the bone (Kapron et al. 2015). Advantages of simulation studies are that no large setup is required and patients are only exposed to radiation in relation to the CT-scan that is used to create bone models. Motion capture systems primarily investigate functional in-vivo hip kinematics during gait or squat, but do not investigate ROM during passive movements (Diamond et al. 2015a; Brisson et al. 2013; Rylander et al. 2011), subluxation of the hip joint (translation of the femur center of rotation with respect to the femur) and bone-bone distances due to soft tissue artifacts (Taylor et al. 2005). Kapron et al. used dual fluoroscopy and a digitally reconstructed radiograph based analysis method for tracking bone movements during flexion, adduction and internal rotation (FADIR), and investigated in vivo kinematics of the hip joint in three FAI-patients and six non-FAI participants (Kapron et al. 2015; Kapron et al. 2014). They found that the FAI-group had decreased adduction and internal rotation during passive tests and further that ROM is governed by labrum contact and other soft tissue restraints in the native joint. They did not investigate post-operative changes in kinematics.

The pathomechanics for development of symptoms in FAI are not well understood, and neither are the kinematic changes in relation to arthroscopic surgery. The establishment of methods for understanding the objective kinematic changes in the hip joint following $\mathrm{ACH}$ will provide evidence of the efficacy of surgery (Bedi et al. 2011).

The aim of this study was to establish methods for evaluation of hip-joint kinematics before and after $\mathrm{ACH}$. Human cadaveric specimens without FAI were used in the experiments. We hypothesized that increased hip ROM (rotations) would be measureable with model-based dynamic RSA (mbRSA) after ACH surgery.

\section{Methods}

\section{Specimens}

Seven human cadaveric legs including hip joints and hemipelvises, from 4 donors were used in the study (Department of Biomedicine, Aarhus University). The age of the donors ranged between 58 and 94 years, three were from male- and four from female donors. Inclusion criterion was no prior hip surgery, which was assessed by $\mathrm{x}$-ray of the hip and visual inspection for earlier surgical incisions. The study was approved by The Central Denmark Region Committees on Health Research Ethics (Case number 1-10-72-6-16 issued on February 24th, 2016).

The donor legs were scanned in a computed tomography $(\mathrm{CT})$ scanner (Brilliance 64, Philips Healthcare, Cleveland, OH, USA). Settings were $120 \mathrm{kV}, 150 \mathrm{mAs}$, slice thickness $2.5 \mathrm{~mm}$ and slice increment $1.25 \mathrm{~mm}$. Bone models were created using an automatic graph-cut segmentation method (Krčah et al. 2011; de Raedt et al. 2013). Bone segmentations of the pelvis included the iliac-, ischial- and pubic bone and for the femur the head down to 5-7 $\mathrm{cm}$ distally to the lesser trochanter. All segmentations were visually inspected and verified to be within voxel accuracy $(<0.3 \mathrm{~mm})$. Local coordinate systems were created for the bone models by the method described by Wu et al. (Wu et al. 2002).

\section{Experimental setup and equipment}

A portable fixation for the hemipelvises which could be mounted both to the radiology table during recordings and in an operative setting during $\mathrm{ACH}$ was constructed (Figs. 1, 2, 3 and 4). Fluoroscopy was made possible from the medial side and used for entering the joint and evaluating the amount of traction applied. Traction was applied using a winch by pulling on a strap around the distal femur. $\mathrm{ACH}$ was performed with a $70^{\circ}$ wide angle arthroscope, a radiofrequency wand (super multivac 50), burr (5.5 mm barrel burr) and a shaver (dyonics incisor plus), (all surgical equipment was provided by Smith and Nephew, London, United Kingdom). Resection was performed by an experienced arthroscopist with simulation of usual FAI-surgery, allthough the donor hips were not FAI hips by radiological definitions. The surgeon restored what appeared to be normal morphology in accordance with the Danish Hip Arthroscopy Registry (DHAP) (average circumferential area of $116^{\circ}(\mathrm{SD}=24.5)$ and a mean depth of $3.8 \mathrm{~mm}(\mathrm{SD}=1.7)$ (Lund et al. 2017).

\section{Radiographic setup}

All stereoradiographs were recorded using a dynamic RSA system (Adora RSAd, NRT X-Ray, Denmark). Sampling frequency was five frames/s, pulse width $16 \mathrm{~ms}$. Roentgen tubes were positioned with a $45^{\circ}$ cranio-caudal- and $20^{\circ}$ medio-lateral tilt directed at the 


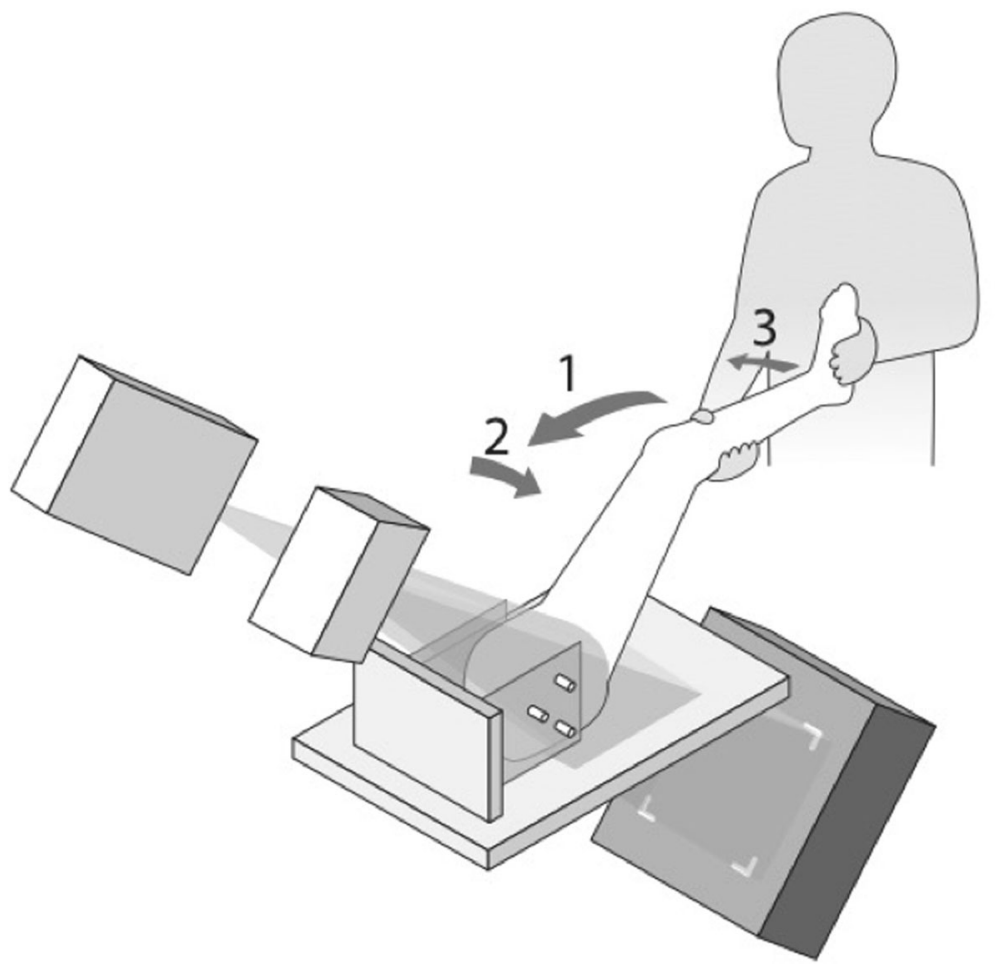

Fig. 1 Setup of the radiostereometric equipment. The $x$-ray tubes were positioned with $20^{\circ}$ medio-lateral and $45^{\circ}$ cranio-caudal tilt. The calibration box was placed in a $45^{\circ}$ angle beneath the hip joint. The FADIR motion is indicated by the numbered arrows: 1) Flexion to $90^{\circ}$ 2) adduction to stop 3) internal rotation to stop

hip joint from the cranial-caudal direction. Beneath the table a uniplanar calibration box (Box 14; Medis Specials, Leiden, the Netherlands) was placed in a $45^{\circ}$ angle to the horizontal plane (Fig. 1). The two image detectors (Canon CXDI-50RF) were slotted in the calibration box. Source image distance (SID) was $2220 \mathrm{~mm}$ and focus skin distance (FSD) $1140 \mathrm{~mm}$. Exposure settings for dRSA recordings were $130 \mathrm{kV}, 500 \mathrm{~mA}, 16 \mathrm{~ms}$ and resolution was 1104x1344 pixels (79 DPI).

\section{Test protocol}

Preoperatively the cadaver specimens were CT-scanned and ARSA was performed. One dynamic RSA recording of the hip during FADIR motion, which is the movement of the donor leg from full extension through flexion aiming at $90^{\circ}$, adduction to stop, and internal rotation to stop (end range) was made (Fig. 1). The FADIR motion was performed slowly due to low frame rate and to ensure a controlled motion. $\mathrm{ACH}$ was performed by

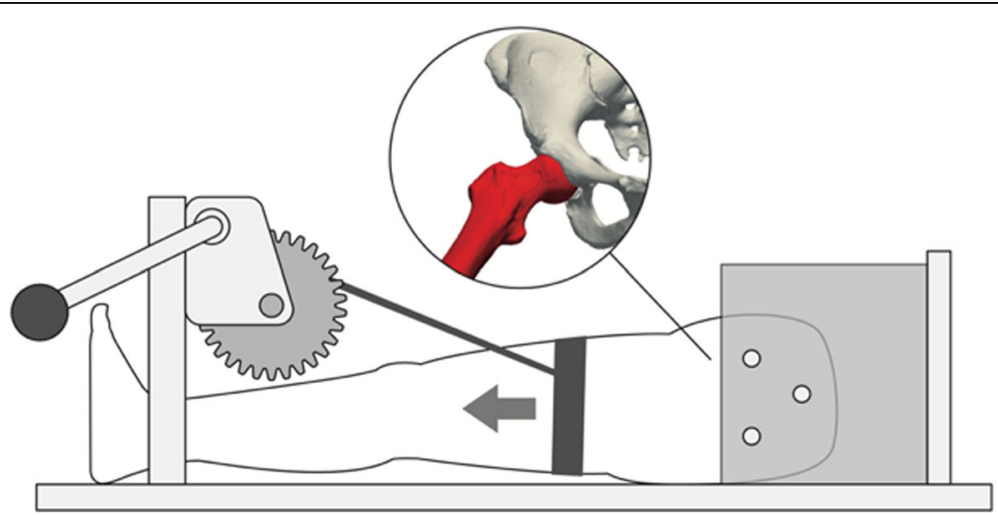

Fig. 2 The surgical setup. The pelvis was mounted in a portable fixture using three spiral drills. Traction was applied using a winch which could be adjusted in height to change flexion angles during $\mathrm{ACH}$ 


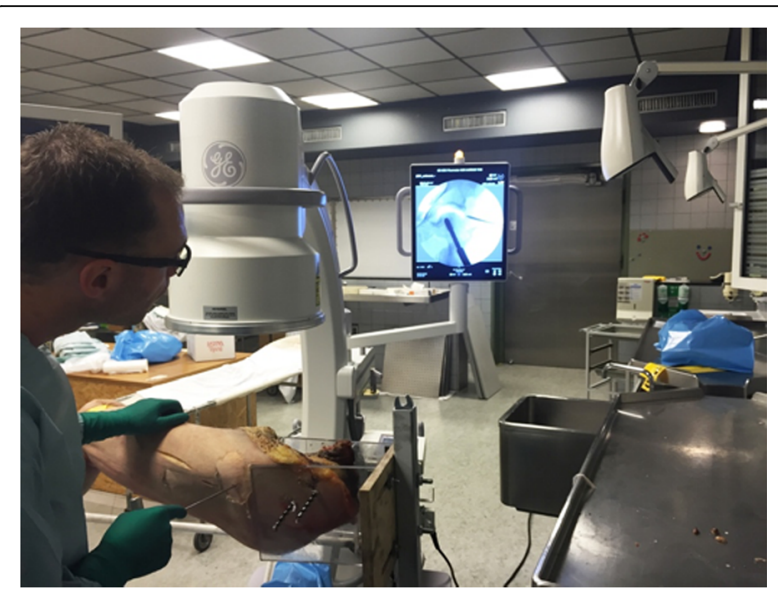

Fig. 3 Images of the surgical setup during $\mathrm{ACH}$. The lateral portal was placed using fluoroscopic guidance

the senior surgeon (BMK). Postoperatively dRSA was repeated and a postoperative CT-scan of each specimen was performed.

\section{Analysis of radiographs}

For analysis of radiographs the commercially available software model-based RSA 4.01 (RSAcore, LUMC, Leiden, The Netherlands) was used. For each specimen calibration of the image was performed in the first frame. For the mbRSA-analysis the created bone models were implemented in the software program. Contours of the pelvicand femur bones were detected on the two simultaneous images of the same scene by the Canny Edge Detector and relevant contours were manually identified, aiming to use similar contours in each frame (Kaptein et al. 2004). The software automatically positions the bone models using three consecutive algorithms: IIPM, DIFDHSAnn and DIFDoNLP. These algorithms estimate the pose by

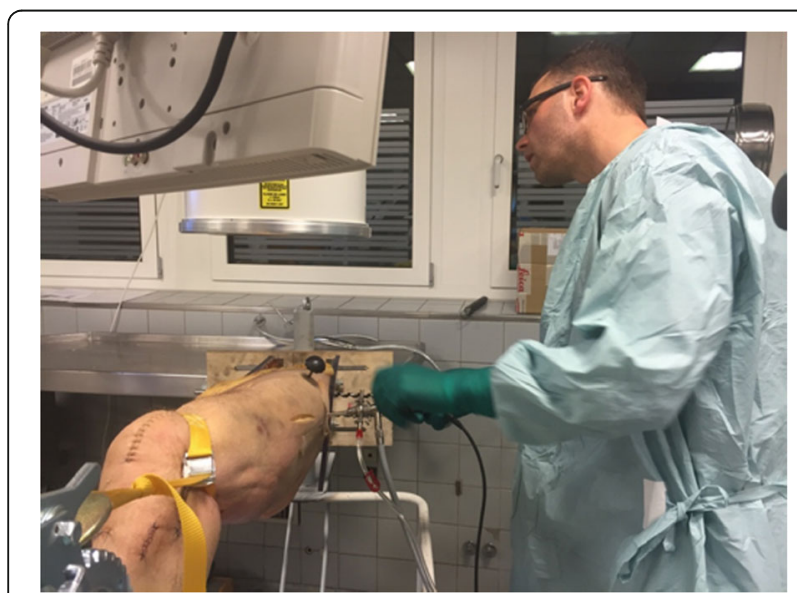

Fig. 4 Images of the surgical setup during $\mathrm{ACH}$. The lateral portal was placed using fluoroscopic guidance minimizing error between the virtual projections of the bone models and the manually detected contours on the radiographs (Kaptein et al. 2004). For each specimen the frame in the sequence, in which the hip was in end range FADIR, was identified and used to determine flexion, adduction and rotation angles of the hip joint (calculated according to the ISB recommendation (Wu et al. 2002) along with femoral end-range subluxation (the norm $\left(\mathrm{T}^{2}=X^{2}+\mathrm{Y}^{2}+\mathrm{Z}^{2}\right)$ of translations of the femur bones' center of rotation with respect to the pelvis). The translation was the difference in position of the center of the femur between two frames in the femur coordinate system.

The CT-scans of the separated hemipelvises were aligned with the contralateral side to determine the anatomic coordinate system and subsequently the lateral center-edge angle (CE) and alpha angle were calculated to determine the preoperative degree of FAI by Clinical Graphics (Delft, The Netherlands).

The volume of removed bone after $\mathrm{ACH}$ was determined by aligning the pre- and post-operative CT scans using image registration and segmenting the region with an intensity change above 50 Hounsfield units (Klein et al. 2010). The resulting model represents the post-operative bone showing the area where bone was removed during $\mathrm{ACH}$. The depth of the removed bone was calculated as the distance from each point of the post-operative surface to the closest point on the pre-operative surface (Fig. 5).

\section{Radiation dose}

Based on real time dRSA recordings dose-calculations were performed. The revealed effective dose per exposure was $0.054 \mathrm{mSv}$. Recordings were acquired at 5 frames/s with a mean exposure time of $9 \mathrm{~s}$ giving an effective dose of $2.43 \mathrm{mSv}$ per recording. The CT-scan contributed with an effective dose of $10 \mathrm{mSv}$ per scan. Total effective dose was $24.86 \mathrm{mSv}$ per specimen.

\section{Data analysis}

Data was summarized as flexion-, adduction- and internal rotation angles as measures of ROM. Paired t-tests were used to compare pre- and postoperative results. Scatterplots of the volume of removed bone against flexion, adduction and internal rotation respectively were constructed to check for correlations. End range sub-luxation was measured as the norm of translations along the $\mathrm{x}-, \mathrm{y}$ - and $\mathrm{z}$-axes by use of the 3D Pythagorean theorem $\left(\mathrm{T}^{2}=X^{2}+\mathrm{Y}^{2}+\mathrm{Z}^{2}\right)$. Preand postoperative sub-luxation was compared using paired t-tests. The statistical significance level was set to 5\% and Stata/IC 14.1 (StataCorp, College Station, Texas, USA) was used for statistical analyses. 

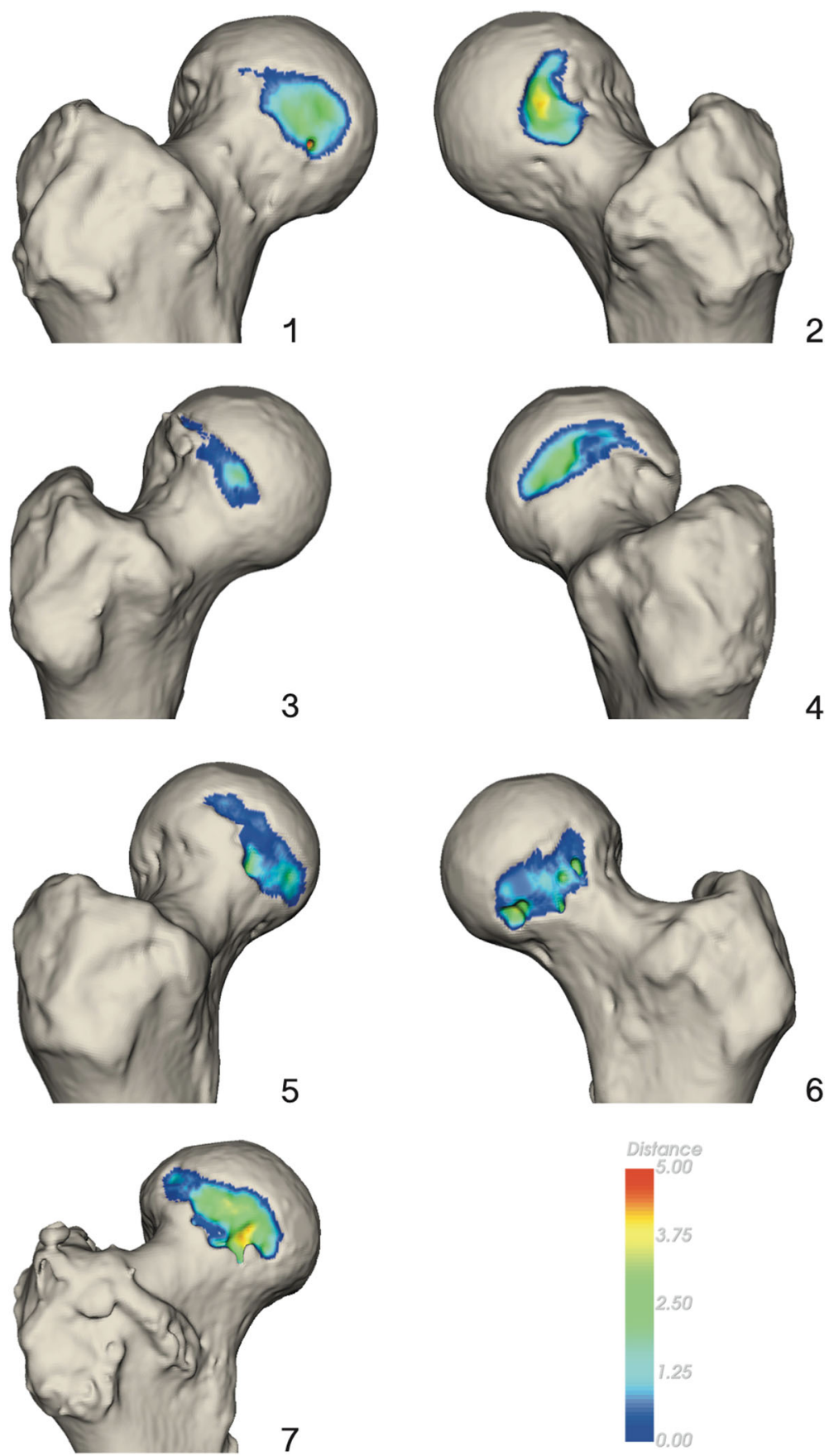

Fig. 5 Figure showing the area and depth of resected bone during ACH for all seven donor hips. The color scale refers to depth of resection in millimeters

\section{Precision of mbRSA}

In an earlier validation study, we have validated dynamic mbRSA as a method for evaluation of hip kinematics in FAI (unpublished work). Validation was performed using traditional marker based RSA as gold standard. Precision of mbRSA described as 95\% limits of agreement ( \pm LOA) (standard deviation * 1.96) were below $0.44 \mathrm{~mm}$ for translations of the femur, below $0.91 \mathrm{~mm}$ for translations of the pelvis and below $0.7^{\circ}$ in rotations for both the femur and pelvis.

\section{Results}

The kinematic results showed a postoperative mean increase in hip rotation of $2.79^{\circ}$ (SD 2.7; $p=0.04$ ). No increase in adduction was observed (mean difference $1.23^{\circ}, \mathrm{SD} 4.3 ; p=0.48$ ) and no statistical difference in 


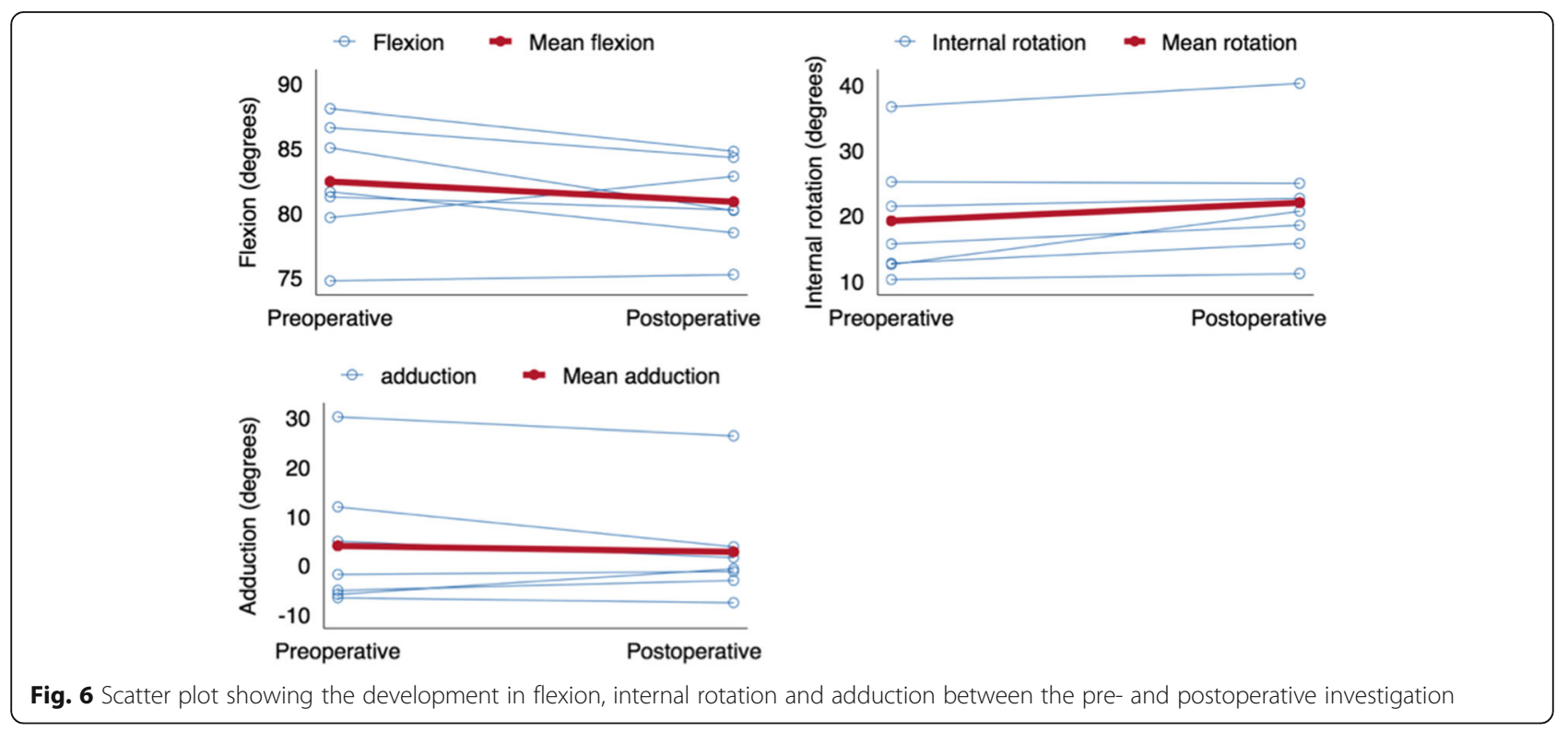

flexion was found between pre- and postoperative recordings, mean difference $-1.57^{\circ}$ (SD 2.7; $p=0.18$ ) (Fig. 6). Mean pre- and postoperative flexion angles were 80.8 and $82.4^{\circ}$ respectively. The flexion angles for the individual donors varied between 75 and $87^{\circ}$ but no significant development from pre- to postoperative was observed (Fig. 6). No correlation was found between ROM and volume of removed bone (Fig. 7).

A large variation in the volume of removed bone on the femur was observed with a mean volume of $894 \mathrm{~mm}^{3}$ (SD $459 \mathrm{~mm}^{2}$ ) and minimum and maximum values of 335 and $1609 \mathrm{~mm}^{2}$ (Table 1).

Mean pre- and postoperative subluxation at end range FADIR, 3.9 and $3.5 \mathrm{~mm}$ respectively, did not differ significantly (SD 0.96; $p=0.37$ ). Also no differences were observed $(p>0.05)$ when comparing the translations for the individual degrees of freedom.

Measurements of $\mathrm{CE}$ and alpha-angles revealed that none of the donor hips had a cam-lesion $\left(\alpha<55^{\circ}\right)$ but showed that two of the donors had a $\mathrm{CE}>40^{\circ}$ and thereby per definition a pincer-lesion (Table 1).

\section{Discussion}

Dynamic radiostereometry was used to investigate kinematic angles in the hip joint of human cadaver specimens during a passive FADIR motion before and after $\mathrm{ACH}$, and the key finding was a small statistically significant increase of $2.79^{\circ}$ in internal rotation but no increase in adduction. The mean removed bone was $894 \mathrm{~mm}^{3}$.

The use of cadaver specimens make up the best imitation of a clinical setting and we have shown mbRSA evaluation of hip kinematics to be very precise (see "Precision of mbRSA"). However, there are a number of limitations in this study related to the use of cadavers. After $\mathrm{ACH}$ the joint space was meticulously emptied for excess water to reduce the influence on measurements. However, the increase in internal rotation was smaller than expected and might be explained by water accumulation in the tissue around the hip causing edema and rigidity. No difference in pre-and postoperative hip joint subluxation was observed, and therefore eventual loss of muscle tone stabilization after traction on the hip joint and eventual postoperative capsule laxity after distension during arthroscopy cannot explain the small post-operative increase in hip ROM. Since flexion angles did not differ significantly, they too do not explain the low increase in internal rotation. In patients, we would expect blood circulation and recovery time after surgery before control measurements would be possible to eliminate this limitation and provide greater kinematic improvements after $\mathrm{ACH}$.

Due to the high age of specimens the bone quality was low and labrums were calcified, which made it more difficult to determine the border between the labrum and the acetabular bone on the CT-scans. Hereby, much of the labrum was segmented along with the bone during model-construction making the pelvis bone model less accurate in the acetabular rim region. Therefore, measurements of the $\mathrm{CE}$ angle are expected to be higher and it was not possible to measure the amount of bone removed from the acetabulum. Further, the inability to differentiate between the bone and the labrum made it impossible to measure bone-bone distances at impingement and determine whether the bones collided at end range FADIR. Further, the low bone quality influenced the conditions for bone removal at a consistent depth because the burr would easily penetrate into the bone in soft regions. This may have contributed to the large variation between subjects in volume of removed bone. 

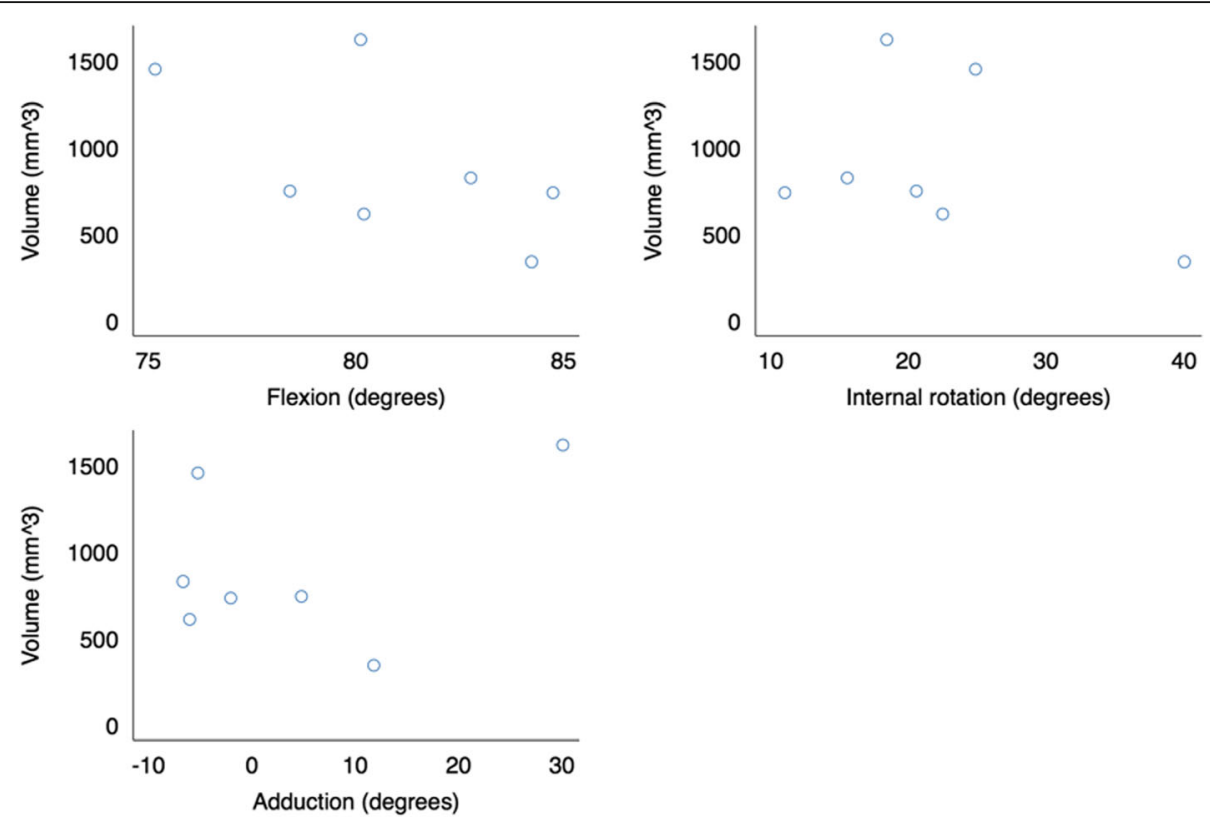

Fig. 7 Scatter plots of the volume of removed bone with respect to the postoperative flexion, internal rotation and adduction

The cadaver fixture and fixation had to allow for stereoradiography and therefore only a small area of the ilium could be used to ensure that the fixation did not block the $x$-rays. At end range FADIR the mean preand postoperative hip flexion angles were measured to be 80.8 and $82.4^{\circ}$ with RSA, while we anticipated to reach $90^{\circ}$ clinical flexion during testing. This may also be attributed to the use of cadaveric hemipelvises which made it more difficult to estimate the exact flexion angle during the experiment. Yet, due to the variation in pelvic tilt and the variation between patients this may also be a challenge in clinical studies. However, reproducibility to reach the same flexion position pre- and post-operative was good with a mean difference of $-1.57^{\circ}$.

The CT-scans and RSA examinations contributed with a combined effective dose of $24.86 \mathrm{mSv}$. During the study further tests have been performed on the required quality of the CT-scans. A new CT-scanner has been installed at our institution and the field of view has been decreased to include only the joint space for the postoperative scan. This will allow for a substantial dose reduction of the CT-scans to $5.2 \mathrm{mSv}$ for the preoperative scan and further reduction for the postoperative scan, which is necessary for estimating the volume of resected bone. In addition further reductions in the effective dose of the RSA examinations will and can be achieved. The reduction in radiation dose will justify the use of mbRSA for future clinical use in FAI patients, when taking the severity and prevalence of FAI into account (Radiation protection 99, EU guidelines). Furthermore, the kinematics can be determined without the post-operative CT scan by using the models created from the pre-operative CT scan, which would further reduce the dose in clinical use. However, then no estimate of the removed bone can be calculated.

To our knowledge only one very small numbered invivo RSA study evaluating hip joint kinematics has formerly been conducted. Kapron et al. used a digitally reconstructed radiograph based method for preoperative in vivo kinematic investigations of the hip on six normal subjects and three symptomatic FAI subjects. They suggested that the restriction of hip ROM is governed by the labrum and other soft tissue constraints (Kapron et al. 2015). Since only three symptomatic FAI patients were included, no statistical comparison was performed. For the asymptomatic group Kapron et al. found a mean internal rotation of $19^{\circ}$ and a mean adduction of $11^{\circ}$. In comparison, we found a similar mean preoperative internal rotation of $19.1^{\circ}$ but a lower mean adduction of $3.9^{\circ}$. The mean adduction found in this study was comparable to the results of the symptomatic group found by Kapron et al. Roach et al. have investigated digital inclinometer and goniometer for measuring passive hip motion and found these methods to be associated with errors up to $5^{\circ}$ (Roach et al. 2013). Hence, these methods would not be feasible for measuring the differences in ROM found in this study nor for measuring the differences between subjects (Kapron et al. 2015).

The pain reduction after $\mathrm{ACH}$ that has been reported in patients might not be caused by improved adduction and internal rotation but by a reduction in labral stress 
Table 1 Table showing the preoperative CE- and alpha angle and volumes of removed bone during ACH for the seven donor hips

\begin{tabular}{lccl}
\hline Donor ID & CE $\left(^{\circ}\right)$ & Alpha $\left(^{\circ}\right)$ & Volume $\left(\mathrm{mm}^{3}\right)$ \\
\hline 1 & 39.5 & 43.0 & 816 \\
2 & 43.1 & 48.3 & 734 \\
3 & 39.2 & 43.4 & 335 \\
4 & 47.4 & 43.2 & 1609 \\
5 & 36.8 & 48.1 & 604 \\
6 & 36.7 & 42.3 & 724 \\
7 & 28.1 & 51.6 & 1439 \\
\hline
\end{tabular}

in the resected regions (Nwachukwu et al. 2015; Sansone et al. 2016). Applying mbRSA for evaluation of FAI hips in a clinical study could provide further insight of the in-vivo pathomechanics of FAI and the mechanisms causing pain. mbRSA has proven to be an applicable tool for in-vivo bone tracking and has potential to be used for evaluation of other corrective interventions of the hip such as periacetabular osteotomy in hip dysplasia (Liu et al. 2015; Murphy et al. 2016). A better understanding of the biomechanics relating to various hip conditions may improve the understanding of the etiology and thereby improvements in treatment and surgical correction.

In this study we have shown that hip internal rotation increases after $\mathrm{ACH}$ in cadaver hips, that flexion angles during a passive FADIR test may be reproduced, and that the volume of removed bone on the femur can be quantified. Importantly, the study has provided valuable knowledge concerning the RSA set-up, exposure settings, CT-protocol, patient-positioning and other details needed in order to apply dynamic RSA with bonemodels in clinical use for evaluation of hip kinematics. In the future, this method may provide surgeons with the necessary insight to further improve patient outcome and satisfaction when using $\mathrm{ACH}$.

\section{Abbreviations \\ ACH: Arthroscopic cheilectomy and -rim trimming; CE: Center-edge angle; dRSA: Dynamic RSA; FADIR: Flexion, adduction and internal rotation; FAl: Femoroacetabular impingement; FSD: Focus skin distance; HRQoL: General health-related quality of life; mbRSA: Model-based radiostereometric analysis; ROM: Range of motion; SID: Source image distance}

\section{Acknowledgements}

We would like to thank Lars Lindgren, Lone Rømer and Lissy Fogh Kristiansen from the Department of Radiology, Aarhus University Hospital, for great contributions to data acquisition and Lone Rømer for substantial contributions to the study design. Thanks to the technicians at the Technical Department, Aarhus University Hospital, for contributions to manufacturing of the setup. The study was performed under the Innovation Fund Grant 69-2013-1 "Transforming radiological technology for assessment of implant fixation: from research tool to clinical application".

\section{Funding}

The Novo Nordisk Foundation.

The Danish Rheumatism Association.
Orthopaedic Research Foundation, Aarhus.

Danish Orthopaedic Society Foundation.

\section{Authors' contributions}

LH: made a substantial contribution to the research design, data acquisition and interpretation and writing the first manuscript. SR: made a substantial contribution to the research design, data analysis and interpretation and critical revisions of the manuscript. PBJ: made a substantial contribution to the research design, data acquisition and critical revisions of the manuscript. BMK: made a substantial contribution to the research design and data acquisition. BK: made a substantial contribution to the data analysis and interpretation and critical revisions of the manuscript. MS: made a substantial contribution to the research design, data acquisition and interpretation and critical revisions of the manuscript. All authors read and approved the final manuscript

\section{Competing interests}

We declare that we have no financial or personal relationships with other people or organizations that could inappropriately influence (bias) our work.

\section{Consent for publication}

Not applicable.

\section{Ethics approval and consent to participate}

Statement attached. No need for approval according to The Central Denmark Region Committees On Health Research Ethics. Reference number 1-10-72-6-16.

\section{Publisher's Note}

Springer Nature remains neutral with regard to jurisdictional claims in published maps and institutional affiliations.

\section{Author details}

${ }^{1}$ Department of Orthopedic Surgery, Aarhus University Hospital, Aarhus, Denmark. ²Orthopedic Research Unit, Aarhus University Hospital, Tage-Hansens Gade 2, building 10A, Office 13, 8000 Aarhus, Denmark. ${ }^{3}$ Department of Clinical Medicine, Aarhus University, Aarhus, Denmark. ${ }^{4}$ NRT X-RAY, Hasselager, Denmark. ${ }^{5}$ Department of Orthopaedics, Leiden University Medical Center, Leiden, the Netherlands.

Received: 20 January 2017 Accepted: 26 May 2017

Published online: 05 June 2017

\section{References}

Agricola R, Waarsing JH, Arden NK et al (2013) Cam impingement of the hip-a risk factor for hip osteoarthritis. Nat Rev Rheumatol 9(10):630-634. doi:10. 1038/nrrheum.2013.114

Beck M, Kalhor M, Leunig M, Ganz R (2005) Hip morphology influences the pattern of damage to the acetabular cartilage: femoroacetabular impingement as a cause of early osteoarthritis of the hip. J Bone Joint Surg Br 87:1012-1018. doi:10.1302/0301-620X.87B7.15203

Bedi A, Dolan M, Hetsroni I, et al. Surgical Treatment of Femoroacetabular Impingement Improves Hip Kinematics. Am J Sports Med. 2011; 39(Supplement 1):43S-49S. doi:10.1177/0363546511414635.

Brisson N, Lamontagne M, Kennedy MJ, Beaulé PE (2013) The effects of cam femoroacetabular impingement corrective surgery on lower-extremity gait biomechanics. Gait Posture 37:258-263. doi:10.1016/j.gaitpost.2012.07.016

Casartelli NC, Maffiuletti N a, Item-Glatthorn JF et al (2011) Hip muscle weakness in patients with symptomatic femoroacetabular impingement. Osteoarthr Cartil 19:816-821. doi:10.1016/j.joca.2011.04.001

de Raedt S, Mechlenburg I, Stilling M, Rømer L, Søballe K, de Bruijne M. Automated measurement of diagnostic angles for hip dysplasia. SPIE Med Imaging, Int Soc Opt Photonics. 2013:867009-867009. doi:10.1117/ 12.2007599.

Diamond LE, Wrigley TV, Bennell KL, Hinman RS, O'Donnell J, Hodges PW (2015a) Hip joint biomechanics during gait in people with and without symptomatic femoroacetabular impingement. Gait Posture 43:198-203. doi:10.1016/j. gaitpost.2015.09.023

Diamond LE, Dobson FL, Bennell KL, Wrigley TV, Hodges PW, Hinman RS (2015b) Physical impairments and activity limitations in people with 
femoroacetabular impingement: a systematic review. Br J Sports Med 49(4): 230-242. doi:10.1136/bjsports-2013-093340

Diesel CV, Ribeiro TA, Scheidt RB, De Souza Macedo CA, Galia CR (2015) The prevalence of femoroacetabular impingement in radiographs of asymptomatic subjects: a cross-sectional study. Hip Int 25(3):258-263. doi:10.5301/hipint.5000250

Frank JM, Harris JD, Erickson BJ et al (2015) Prevalence of femoroacetabular impingement imaging findings in asymptomatic volunteers: a systematic review. Arthroscopy 31(6):1199-1204. doi:10.1016/j.arthro.2014.11.042

Freke MD, Kemp J, Svege I, Risberg MA, Semciw A, Crossley KM. Physical impairments in symptomatic femoroacetabular impingement: a systematic review of the evidence. Br J Sports Med 2016:1-19. doi:10.1136/bjsports2016-096152.

Ganz R, Parvizi J, Beck M, Leunig M, Nötzli H, Siebenrock K a (2003) Femoroacetabular impingement: a cause for osteoarthritis of the hip. Clin Orthop Relat Res 417:112-120. doi:10.1097/01.blo.0000096804.78689.c2

Heyworth BE, Shindle MK, Voos JE, Rudzki JR, Kelly BT (2007) Radiologic and intraoperative findings in revision Hip arthroscopy. Arthroscopy 23(12): 1295-1302. doi:10.1016/j.arthro.2007.09.015

Kapron AL, Aoki SK, Peters CL et al (2014) Accuracy and feasibility of dual fluoroscopy and model-based tracking to quantify in vivo hip kinematics during clinical exams. J Appl Biomech 30(3):461-470. doi:10.1123/jab. 2013-0112

Kapron AL, Aoki SK, Peters CL, Anderson AE (2015) In-vivo hip arthrokinematics during supine clinical exams: application to the study of femoroacetabular impingement. J Biomech 48(11):1-8. doi:10.1016/j.jbiomech.2015.04.022

Kaptein BL, Valstar ER, Stoel BC, Rozing PM, Reiber JHC (2004) Evaluation of three pose estimation algorithms for model-based roentgen stereophotogrammetric analysis. Proc Inst Mech Eng H 218(4):231-238. doi:10.1243/095441 1041561036

Klein S, Staring M, Murphy K, Viergever MA, Pluim JPW (2010) Elastix: a toolbox for intensity-based medical image registration. IEEE Trans Med Imaging 29(1): 196-205. doi:10.1109/TMI.2009.2035616

Kowalczuk M, Yeung M, Simunovic N, Ayeni OR (2015) Does femoroacetabular impingement contribute to the development of Hip osteoarthritis? a systematic review. Sports Med Arthrosc 23(4):174-179

Krčah M, Székely G, Blanc R. Fully automatic and fast segmentation of the femur bone from 3D-CT images with no shape prior. Proc Int Symp Biomed Imaging. 2011:2087-2090. doi:10.1109/ISBI.2011.5872823.

Kubiak-Langer M, Tannast M, Murphy SB, Siebenrock K a, Langlotz F (2007) Range of motion in anterior femoroacetabular impingement. Clin Orthop Relat Res 458(458):117-124. doi:10.1097/BLO.0b013e318031c595

Larson CM, Giveans MR, Samuelson KM, Stone RM, Bedi A (2014) Arthroscopic hip revision surgery for residual femoroacetabular impingement (FAl) surgical outcomes compared with a matched cohort after primary arthroscopic FAl correction. Am J Sports Med 42(8):1785-1790. doi:10.1177/ 0363546514534181

Larson CM, Kelly BT, Bhandari M et al (2016) Impingement. Arthroscopy 32(1): 177-189. doi:10.1016/j.arthro.2015.10.010

Liu L, Ecker T, Xie L, Schumann S, Siebenrock K, Zheng G (2015) Biomechanical validation of computer assisted planning of periacetabular osteotomy: a preliminary study based on finite element analysis. Med Eng Phys 37(12): 1169-1173. doi:10.1016/j.medengphy.2015.09.002

Lund B, Mygind-Klavsen B NT et al. Danish Hip Arthroscopy Registry (DHAR): The outcome of patients with femoroacetabular impingement (FAI). J Hip Preserv Surg. 2017:0(0):1-8. doi:10.1093/jhps/hnx009.

Murphy RJ, Armiger RS, Lepistö J, Mears SC, Taylor RH, Armand M (2016) Clinical evaluation of a biomechanical guidance system for periacetabular osteotomy. J Orthop Surg Res 10(4):497-508. doi:10.1007/s11548-014-1116-7

Nwachukwu BU, Rebolledo BJ, McCormick F, Rosas S, Harris JD, Kelly BT. Arthroscopic Versus Open Treatment of Femoroacetabular Impingement: A Systematic Review of Medium- to Long-Term Outcomes. Am J Sports Med. 2015. doi:10.1177/0363546515587719.

Philippon MJ, Schenker ML, Briggs KK, Kuppersmith DA, Maxwell RB, Stubbs AJ (2007) Revision hip arthroscopy. Am J Sports Med 35(11):1918-1921. doi:10. $1177 / 0363546507305097$

Roach S, San Juan JG, Suprak DN, Lyda M (2013) Concurrent validity of digital inclinometer and universal goniometer in assessing passive hip mobility in healthy subjects. Int J Sports Phys Ther 8(5):680-688, http://www.pubmed central.nih.gov/articlerender.fcgi?artid=3811733\&tool=pmcentrez\&render type=abstract
Ross JR, Larson CM, Adeoyo O, Kelly BT, Bedi A (2014) Residual deformity is the most common reason for revision hip arthroscopy: a three-dimensional CT study. Clin Orthop Relat Res 473:1388-1395. doi:10.1007/s1 1999-014-4069-9

Rylander JH, Shu B, Andriacchi TP, Safran MR (2011) Preoperative and postoperative sagittal plane hip kinematics in patients with femoroacetabular impingement during level walking. Am J Sports Med 39(Suppl):36S-42S. doi: 10.1177/0363546511413993

Sampson JD, Safran MR (2015) Biomechanical implications of corrective surgery for FAl : an evidence-based review. Sports Med Arthros 23(4):169-173

Sansone M, Ahldén M, Jónasson P, et al. Outcome after hip arthroscopy for femoroacetabular impingement in 289 patients with minimum 2-year followup. Scand J Med Sci Sports. 2016:n/a-n/a. doi:10.1111/sms.12641.

Taylor WR, Ehrig RM, Duda GN, Schell H, Seebeck P, Heller MO (2005) On the influence of soft tissue coverage in the determination of bone kinematics using skin markers. J Orthop Res 23(4):726-734. doi:10.1016/j.orthres.2005.02.006

Wu G, Siegler S, Allard P et al (2002) ISB recommendation on definitions of joint coordinate system of various joints for the reporting of human joint motion — part I: ankle, hip, and spine. J Biomech 35(4):543-548. doi:10.1016/ S0021-9290(01)00222-6

\section{Submit your manuscript to a SpringerOpen ${ }^{\circ}$ journal and benefit from:}

- Convenient online submission

- Rigorous peer review

- Open access: articles freely available online

- High visibility within the field

- Retaining the copyright to your article

Submit your next manuscript at $\gg$ springeropen.com 